\title{
PHOTOCATALYTIC CONCRETE SCREEDS WITH SELF-CLEANING AND ANTIMICROBIAL FUNCTION
}

\author{
${ }^{1}$ Hana BÍBOVÁ, ${ }^{2} J a n$ ŠUBRT, ${ }^{2} E v a$ PLIŽINGROVÁ, ${ }^{3}$ Michaela JAKUBIČKOVÁ,

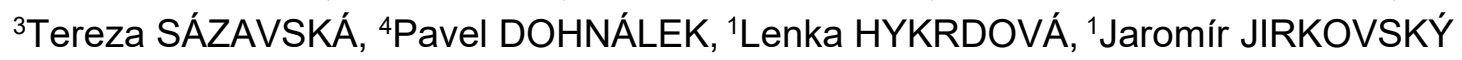 \\ 1J. Heyrovsky Institute of Physical Chemistry CAS, Prague, Czech Republic, EU, \\ hana.bibova@jh inst.cas.cz \\ 2Institute of Inorganic Chemistry CAS, Řež, Czech Republic, EU, \\ subrt@iic.cas.cz \\ ${ }^{3}$ Technial University of Liberec, Liberec, Czech Republic, EU, \\ michaela.jakubickova@gmail.com \\ ${ }^{4}$ Betosan, s.r.o., Prague, Czech Republic, EU, \\ dohnalek.p@betosan.cz
}

https://doi.org/10.37904/nanocon.2019.8515

\begin{abstract}
Photocatalytic concrete screeds with self-cleaning and antimicrobial function have been developed and tested. These building materials contain sand grains with deposited composite $\mathrm{TiO}_{2} / \mathrm{SiO}_{2}$ layers. Two types of the screeds, grey and white, were prepared and their photoactivity and material characteristics were compared. Commercial $\mathrm{TiO}_{2}$ photocatalysts from several manufacturers were employed. Effects of different parameters, such as temperature of the coated sand calcination, humidity, and surface abrasion, were followed. Mechanical properties of the screeds were analyzed by SEM/XRD microscopy. Photocatalytic activity was tested by means of $\mathrm{NO}_{x}$ oxidation (ISO norm 22197-1/2007). Antibacterial activity was evaluated by modified ISO norm $27447 / 2009$ with Bacillus subtilis as a model organism.
\end{abstract}

Keywords: Self-cleaning screed, photodegradation, $\mathrm{NO}_{x}, \mathrm{SEM}$, antimicrobial activity

\section{INTRODUCTION}

The use of advanced oxidation processes such as photocatalysis in the development of new technologies and materials is a subject of applied research. In the construction industry, innovative formulas for cements, concretes and screeds with self-cleaning properties, based on photocatalytic reaction after exposure to UV radiation are still being developed and improved [1-3]. Nevertheless, the self-cleaning function of these surfaces is not their only advantage. There are at least three benefits, although the third is marginal:

1) Self-cleaning - concrete surfaces which remain clean over the long periods of time (the aesthetic aspect);

2) Antimicrobial function - eliminating bacteria, viruses, moulds, algae (the sanitary aspect);

3) Reducing air pollutants (the ecological aspect).

The goal of our research was to characterize and test the photoactive screeds prepared according to evolutionarily modified recipes. The screeds, typically in a layer of 3 to $5 \mathrm{~mm}$, have been formulated in two colour variants: a basic grey and an innovative white variant based on white Portland cement. These materials are primarily intended for exterior applications, such as the self-cleaning outer shell of buildings, as well as treatment of the surface layer of various structures such as bridges, noise barriers, traffic barriers and tunnels. The developed materials could also be used in interiors under specific conditions (exposed to lighting from UV LEDs), primarily finding uses in the health care and food processing industries. 


\section{METHODOLOGY AND MATERIAL}

Preparation of the screeds: Photoactive layer represented by $\mathrm{SiO}_{2} / \mathrm{TiO}_{2}$ composite was deposited on homogeneous, clean and free of impurities quartz sand according to the following procedure. As a binder, a colloid form of water glass $\left(\mathrm{SiO}_{2}\right)$ was applied first [4]. Deposition of the photocatalyst $\left(5 \%\right.$ aqueous $\mathrm{TiO}_{2}$ suspension in a volume ratio 1:1 with the sand) proceeded under vigorous stirring on a shaker for 2 hours, followed by filtration and drying of the sand at laboratory temperature or at $250^{\circ} \mathrm{C}$.

The prepared sand was subsequently used in two colour variants of the screeds: grey (FotoFix Grey; FFix G) and white variant based on white Portland cement (FotoFix White; FFix W).

Samples of each variant were prepared in 3 modifications:

- $\quad 0$ : With sand without photocatalytic layer (control),

- 1 : With sand with $\mathrm{TiO}_{2} / \mathrm{SiO}_{2}$ layer dried at $250{ }^{\circ} \mathrm{C}$,

- 2: With sand with $\mathrm{TiO}_{2} / \mathrm{SiO}_{2}$ layer dried at room temperature.

The above variants were characterized in Betosan, s.r.o., concerning regular "construction" parameters, such as workability of the materials in fresh state and further test of the basic physical parameters such as volumetric weight, flexural tensile strength, compressive strength (ČSN EN 12190) and adhesion to the substrate (ČSN EN 1542). The non-sagging test consisted of fixing a tile at an angle of $80^{\circ}$ to simulate the vertical position of the surface and using a masonry trowel, the tested material was applied. The temperature testing was carried out at temperatures of +5 and $+40{ }^{\circ} \mathrm{C}$, when the components were heated to a given temperature and after mixing they were applied to tiles of the same temperature. The tests were performed in duplicate and classified in a scale of 1 to 5 ( 1 being the best).

Photocatalytic activity of sand and screed samples was determined according to the modified ISO norm 22197$1 / 2007$ [5] by oxidation of NO. The surface of the sample $\left(50 \mathrm{~cm}^{2}\right)$ was irradiated with a UVa lamp (Philips BLB $15 \mathrm{~W}, 365 \mathrm{~nm}$ ) with an intensity of $1.0 \mathrm{~mW} . \mathrm{cm}^{-2}$ for sand and $3.6 \mathrm{~mW} . \mathrm{cm}^{-2}$ for screed samples. The gaseous mixture of NO (1 ppmv) and synthetic air ( $50 \%$ humidity) linearly flowed through the apparatus $\left(3 \mathrm{~L} \cdot \mathrm{min}^{-1}\right)$ and formed NOx were analyzed by chemiluminiscence Horiba 370 NO-NOx gas analyser. Photocatalytic effectiveness was evaluated based on the size of the initial conversion of the concentration of NO directly after start of radiation and further at limit values of $\mathrm{NO}_{x}$ corresponding to photostationary equilibrium.

The samples were studied using the scanning electron microscope Philips XL $30 \mathrm{CP}$. Element analysis and mapping were measured on that attached EDX analyser EDAX PV 9760/77. The nonconductive samples were sputter coated with an alloy of Au-10\%Pd using the vacuum sputter coating device Polaron SC 7640.

Modified ISO norm 27447/2009 [6] was used for determination of the antimicrobial activity of the screeds. A Gram-positive sporulating aerobic bacterium Bacillus Subtilis, that cultivates in strongly alkaline environments typical of freshly prepared concrete materials, and is also commonly found in soils, was used. Concrete plates $(25 \times 25 \mathrm{~mm})$ were first wetted with $10 \mathrm{~mL}$ nutrient substrate, followed by inoculum at $10^{6} \mathrm{CFU} \cdot \mathrm{mL}^{-1}$. In Petri dishes they were exposed to radiation $(365 \mathrm{~nm})$ with an intensity of $1 \mathrm{~mW} . \mathrm{cm}^{-2}$. The identically prepared control samples were left in dark. Exposure time was up to 24 hours.

\section{RESULTS AND DISCUSSION}

Physicochemical properties of the prepared screeds are summarized in Tables $\mathbf{1}$ and 2. None of the modifications of the preparation method adversely affected the processability or physico-mechanical properties of the samples. The only parameter that might become problematic is the lack of adhesion to the substrate observed for the FotoFix G1, W1 and W2 variants, as the resulting values are below the standard value (1.5 MPa). 
Table 1 Workability properties

\begin{tabular}{|c|c|c|c|c|c|c|}
\hline \multirow{2}{*}{ Screed } & \multicolumn{7}{|c|}{ Sample } \\
\cline { 2 - 7 } & FFIX G0 & FFIX G1 & FFIX G2 & FFIX W0 & FFIX W1 & FFIX W2 \\
\hline Ease of application & 1.5 & 1.5 & 1 & 1.0 & 1.5 & 1 \\
\hline Non-sagging & 1.0 & 1.5 & 1 & 1.5 & 1 & 1.5 \\
\hline Temperature & 1.5 & 1.5 & 1.25 & 1.5 & 2 & 2 \\
\hline Summary & 1.33 & 1.5 & 1.08 & 1.33 & 1.5 & 1.5 \\
\hline
\end{tabular}

Table 2 Physico-mechanical tests

\begin{tabular}{|c|c|c|c|c|c|c|}
\hline \multirow{2}{*}{ Screed } & \multicolumn{5}{c|}{ Sample } \\
\cline { 2 - 8 } & FFIX G0 & FFIX G1 & FFIX G2 & FFIX W0 & FFIX W1 & FFIX W2 \\
\hline Volumetric weight $\left(\mathrm{kg} / \mathrm{m}^{3}\right)$ & 1851 & 1868 & 1898 & 1900 & 1879 & 1876 \\
\hline Flexural tensile strength after 7 days (MPa) & 3.4 & 3.9 & 3.8 & 3.1 & 3.4 & 3.8 \\
\hline Flexural tensile strength after 28 days (MPa) & 5.7 & 5.8 & 5.6 & 5.8 & 5.7 & 5.5 \\
\hline Compressive strength after 7 days (MPa) & 16.3 & 16.7 & 18.2 & 18.5 & 16.3 & 17.1 \\
\hline Compressive strength after 28 days (MPa) & 26.9 & 26.7 & 27.5 & 27.8 & 28.4 & 27.3 \\
\hline Adhesion to the substrate after 28 days (MPa) & 1.6 & 1.2 & 1.5 & 1.3 & 1.1 & 1.1 \\
\hline
\end{tabular}

Measurements of photoactivity (photocatalytic oxidation of NO) showed satisfactory efficiency of the sand with the deposited $\mathrm{TiO}_{2} / \mathrm{SiO}_{2}$ composite layer. Up to $24 \% \mathrm{NO}$ conversion (limit conversion), Table 3, was achieved for optimal preparation conditions (drying at the room temperature). On the contrary, high drying temperature (calcination) resulted in a photoactivity decrease.

Table 3 Sand photoactivity: limit values of NO conversion

\begin{tabular}{|c|c|}
\hline Sand modification & Limit NO conversion (\%) \\
\hline 0 & 0 \\
\hline 1 & 18.6 \\
\hline 2 & 24.9 \\
\hline
\end{tabular}

Photoactivity of all screed samples was determined, Table 4. FotoFix White samples showed up to 3 times higher photocatalytic activity than the FotoFix Grey samples. Due to the lower absorption of white cement itself, the photocatalyst particles are activated by a higher number of incident photons than in the case of grey variant.

Table 4 FotoFix White and Grey screeds photoactivity: Initial maximum conversion of NO

\begin{tabular}{|c|c|c|}
\hline Modification & FotoFix W & FotoFix G \\
\hline 0 & 0 & 0 \\
\hline 1 & 2.2 & 0.9 \\
\hline 2 & 2.4 & 0.7 \\
\hline
\end{tabular}

Antimicrobial activity of the FotoFix White (samples FotoFix W0 and W2) was tested and evaluated, Figure 1. According to the observed data, addition of $\mathrm{TiO}_{2}$ to the screed formula results in a deterioration of the bacterial growth conditions. In both samples, the number of living bacteria is reduced to a minimum concentration ( $<0.05$ $\mathrm{CFU} / \mathrm{mL}$ ) after 24 hours of irradiation. 


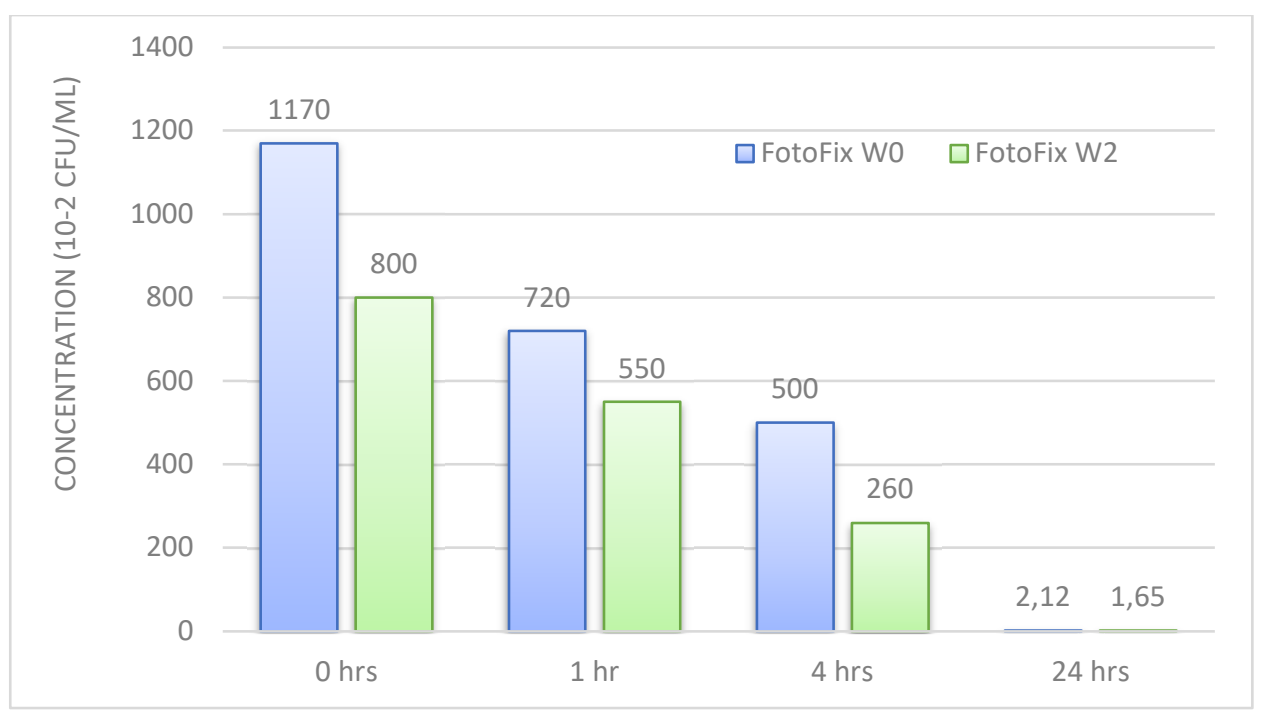

Figure 1 Antibacterial activity (model microorganism Bacillus Subtilis) of FotoFix W0 and FotoFix W2 screeds upon irradiation

Microscopic measurements confirmed that there are 100-300 $\mu \mathrm{m}$ quartz sand grains in the screed samples that are coated with $\mathrm{TiO}_{2}$. This coverage is consistent, the layer thickness is approximately $5 \mu \mathrm{m}$ and there is practically no Ti outside the grains, Figure 2. Figure 3 shows a concrete sample FotoFix W2 containing sand with deposited photocatalytic layer within its volume. It is clearly seen in the EDS mapping that at the sand grains, the signal corresponding to titanium is more pronounced than in the surrounding matrix.
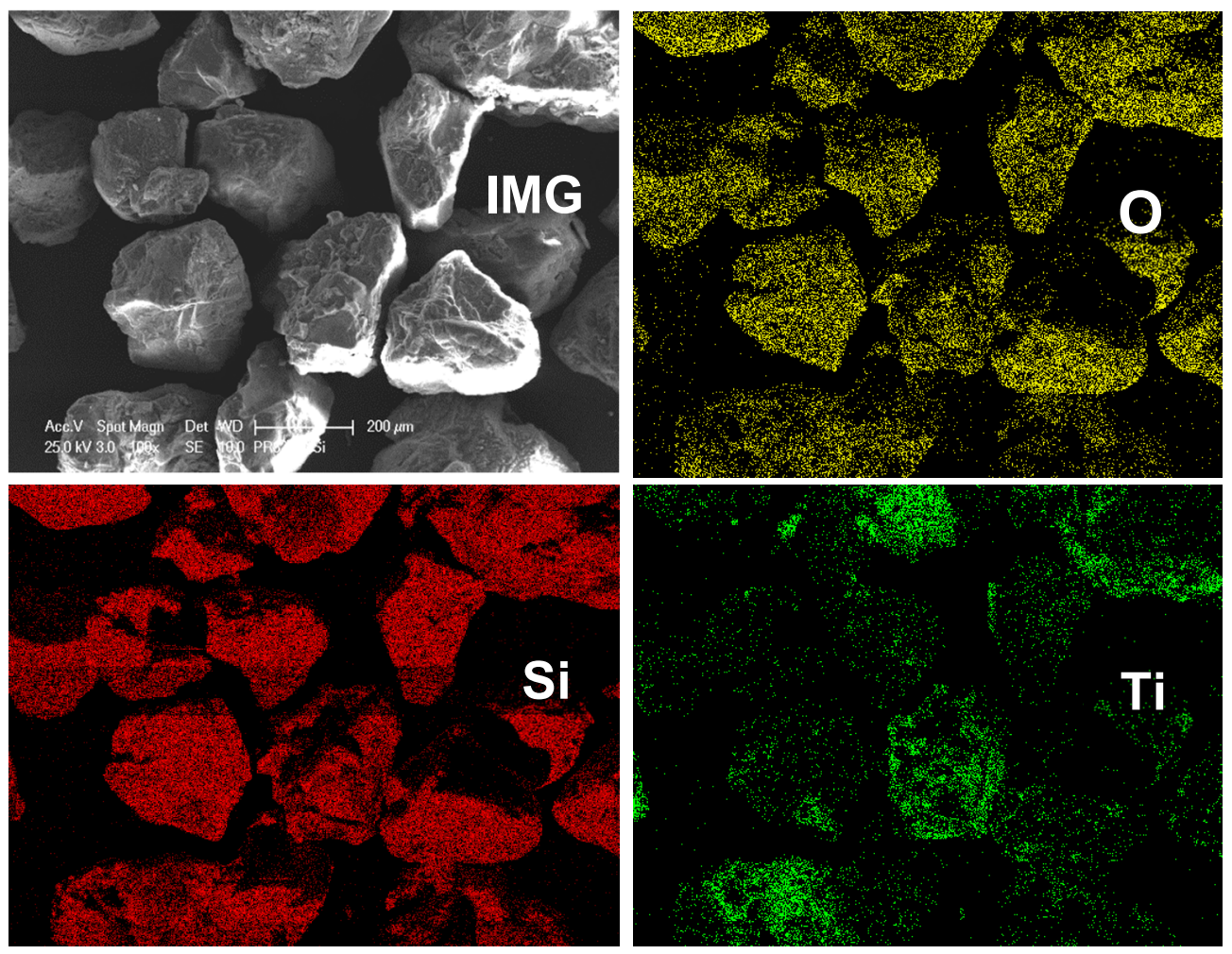

Figure $2 \mathrm{SEM} / \mathrm{EDS}$ elemental mapping of the sample of sand with deposited layer of $\mathrm{TiO}_{2} / \mathrm{SiO}_{2}$ dried at the room temperature (modification 2) 

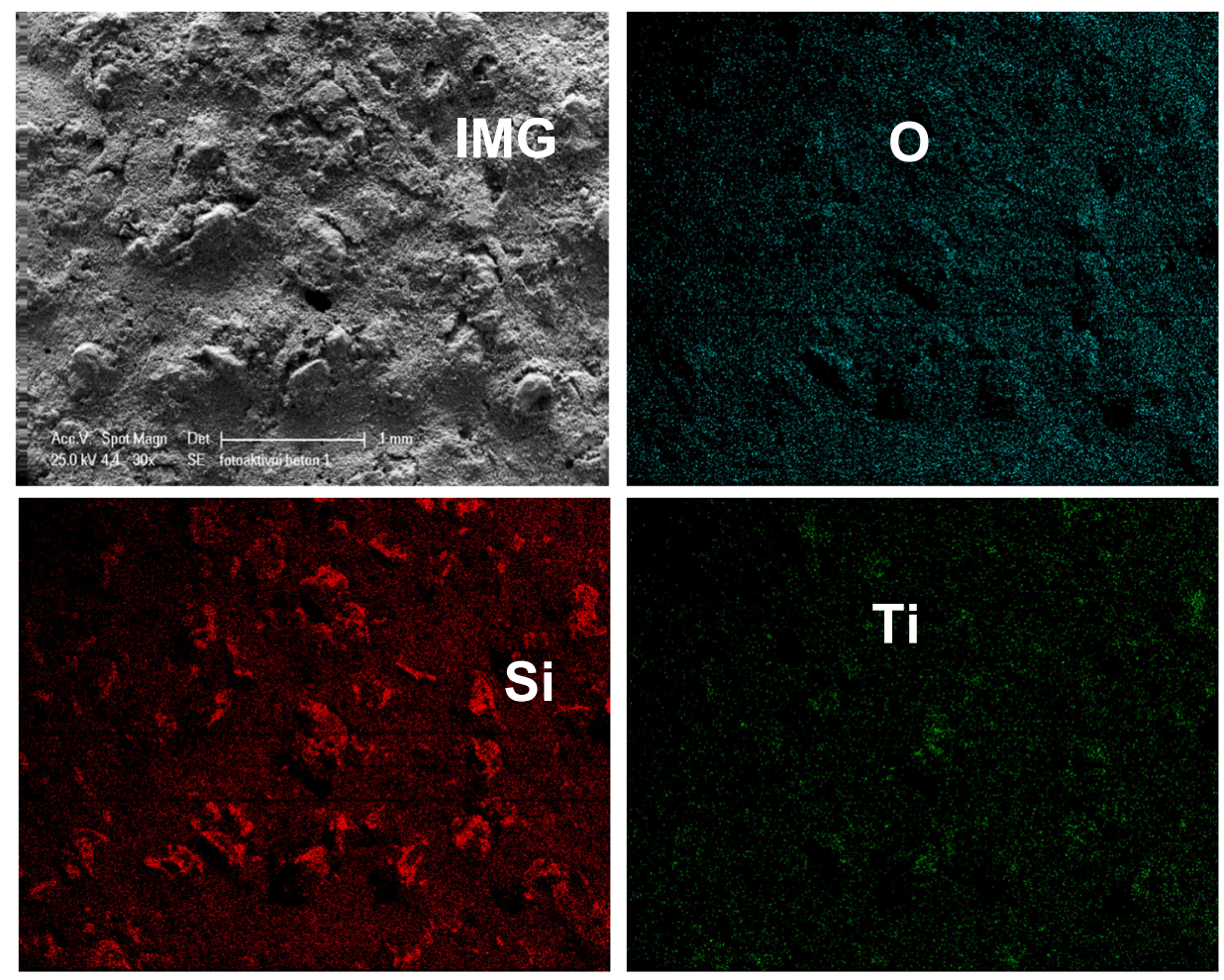

Figure 3 SEM/EDS elemental mapping of the sample of the FotoFix W2 screed

\section{CONCLUSIONS}

The innovative method for production of grey and white self-cleaning concrete screeds using sand with deposited photocatalytic layer was developed. According to the workability tests and physical-mechanical tests, it was confirmed that the screed parameters are not negatively affected by the photocatalyst addition, while maintaining the photocatalytic function. Only the surface adhesion of some of the samples was slightly impaired compared to the standardized value.

SEM/EDS analysis showed that the deposited $\mathrm{TiO}_{2} / \mathrm{SiO}_{2}$ layer is present on sand grains after application and also after the incorporation into the test samples. The photoactivity was measured by means of NO oxidation, where the FotoFix White specimen showed three times higher activity than FotoFix Grey. It was demonstrated that the photocatalytic efficiency was decreased by drying of the sand samples at higher temperature. The results confirmed that antibacterial activity actually occurs on the surface of the developed materials.

\section{ACKNOWLEDGEMENTS}

The theoretical foundations for the presented results were obtained thanks to financial support from the state budget and the Czech Ministry of Industry and Trade via the TRIO programme, under the project head FV20234 "Innovative Photocatalytic Plasters and Concrete Admixtures". The authors acknowledge the assistance provided by the Research Infrastructure NanoEnviCz, supported by the

Ministry of Education, Youth and Sports of the Czech Republic under Project No. LM2015073.

\section{REFERENCES}

[1] BELLARDITA Marianna, ADDAMO Maurizio, Di PAOLA Agatino, MARCì Giuseppe, PALMISANO Leonardo, CASSAR Luigi, BORSA Massimo. Photocatalytic activity of $\mathrm{TiO}_{2} / \mathrm{SiO}_{2}$ systems. Journal of Hazardous Materials. 174, 2010, pp. 707-713. 
[2] BOONEN Elia, BEELDENS Anne, DIRKX Inge, BAMS Veerle. Durability of cementitious photocatalytic building materials. Catalysis Today. 287, 2017, pp. 196-202.

[3] YANG Lu, HAKKI Amer, WANG Fazhou, MACPHEE Donald E. Photocatalyst efficiencies in concrete technology: The effect of photocatalyst placement. Applied Catalysis B: Environmental. 222, 218, pp. 200-208.

[4] BÍBOVÁ Hana, HYKRDOVÁ Lenka, HOANG Hiep, ELIÁŠ Milan, JIRKOVSKÝ Jaromír. $\mathrm{SiO}_{2} / \mathrm{TiO}_{2} \mathrm{Composite}$ coating on light substrates for photocatalytic decontamination of water. Journal of Chemistry. 2019. pp.11. https://doi.org/10.1155/2019/2634398.

[5] International standard ISO 22197-1/2007. FINE CERAMICS (ADVANCED CERAMICS, ADVANCED TECHNICAL CERAMICS). Test method for air-purification performance of semiconducting photocatalytic materials.

[6] International standard ISO 27447:2019. FINE CERAMICS (ADVANCED CERAMICS, ADVANCED TECHNICAL CERAMICS). Test method for antibacterial activity of semiconducting photocatalytic materials. 